Note

\title{
Good practice: Honors course Personal Leadership
}

\author{
Anneke Reintjes and Danielle Poels
}

HU University of Applied Sciences Utrecht, The Netherlands; anneke.reintjes@hu.nl, danielle.poels@hu.nl

Correspondence: anneke.reintjes@hu.nl

Received: 11 July 2018; Accepted: 18 October 2018; Published: 7 January 2019

Keywords: personal leadership, personal development, TopClass

Note to reader: honors keywords (see introductory article of this issue) in italics in the text

\section{Introduction}

The course 'Personal Leadership' is offered at the start of the honors program (TopClass) of the second bachelor year of the Health Care program, HU University of Applied Sciences Utrecht, The Netherlands. It is a course lasting half a year with weekly meetings, on top of the regular program, in a group of 15-17 honors students. It is part of a three year honors program offered parallel with the regular program and totaling a time equivalent of 5 ECTS. A large majority of the students are overwhelmingly positive about the course. The students feel as if they're being respected as people throughout the program. They find the course exciting but difficult at times. Ultimately, they consider the course to be a fruitful and extremely educative experience. During an interview, an alumna mentions the fact that she regards the leadership course as the place where she acquired a different perspective on things. She says: 'The characteristics of effective leadership described in Stephen Covey's book were important to me. Using these characteristics as a basis, interactive meetings were organized. Students were also asked to write a reflection report using the aforementioned characteristics. I still use the things I learned during the course in daily life, as it is useful on both a personal and professional level. This is possible due to the fact that we worked on efficient leadership very consciously for the duration of the course. Especially the concept of "paradigm shift" that Covey often discussed, has brought about a change. The concept focuses on increasing your empathy for others, leading to improved contact with internationals, as well as with patients.'

\section{Why this good practice?}

Students come from an educational system in which everything is reasonably fixed, such as study content, study activities, and exam requirements. They have not yet fully learned how to shape 
their own studies, how to make their own choices related to said studies, or how to approach other people. Therefore, this course aims to further develop personal leadership, which can be described as follows: 'Personal leadership means that you are in charge of your own life. You take responsibility for who you are. You make the choices yourself and do not allow choices to be determined by others. When you allow others to determine it, it is a consciously made choice. You are at the wheel of your own life, you think about what you really care about and where you want to go. Likewise, recognizing your "drive" and developing your qualities as part of an honors program is your own decision. By living so consciously, you also develop as a person. It is about an internally driven development: you "grow" as a person. You can think of dealing with your emotions or difficult situations, increasing your confidence or facing your challenges. You as a person become stronger and more stable. You can position yourself vulnerably in the - constant - process of personal development. You dare to face your mistakes and are prepared to take risks so that you can learn from them. You ask for feedback and reflect on yourself. Your personal development comes from being consistent and focused on a development which comes from within and which is based on your own inner values. Furthermore, developing a safe relationship with the course group (community) is of utmost importance for inspiration, as a safety net, and for mirroring one's own experiences.'

\section{Target group and target group size}

Second year bachelor students of the Health Care program are the target group of this course. The program follows alongside the regular bachelor program. This leadership course lasts half a year with one meeting every two weeks. If a student follows the TopClass, it is their only compulsory course in the honors program. Part-time students can also opt to take this course. In 10 active meetings students are challenged to get to know themselves better and to investigate what suits them. If they finish the course successfully, students are awarded the equivalent of $5 \mathrm{EC}$, which do not count for their regular bachelor program but which fulfills the requirement for an honors star. At the HU University of Applied Sciences Utrecht, a 'star' system has been developed for the honors program, in which students can take part in individually chosen activities and can propose to obtain a 'star-qualification.' The achieved star can become part of an honors qualification for the student. These activities can have both a curricular and an extra-curricular component (Riteco, Kleyn, \& Lamerichs, 2017).

\section{Educational design (structure)}

The TopClass (honors program) starts with a Personal Leadership course (Van Eijl \& Pilot, 2016). The TopClass encourages students to get more out of themselves and take responsibility for their own development (personal development). The leadership course lasts half a year and is the only compulsory course in the TopClass. In the two years that follow in the honors program, students decide for themselves what, how, and with whom they want to learn. This requires personal leadership, creativity, and perseverance, which is why the program starts with this course. In 10 active meetings students are challenged to get to know themselves better and to investigate what suits them. Awareness is the key word. It is therefore not about giving guidance to others but about giving guidance to yourself, making choices from authenticity that ultimately can lead to actual leadership. 


\section{Contents of the course}

The content of the course is related to the seven habits of highly effective people described by Stephen Covey (1989). These habits are briefly summarized as follows:

An overview of the seven habits:

1. Be proactive (anticipate, take initiative, and do not be reactive).

2. Start with the end in mind (what do you want people to say about you at your funeral?).

3. Start at the beginning (focus initially on what is urgent and important).

4. Think in terms of win-win (strive for mutual benefit in all interactions).

5. Try to understand first, only then to be understood (try to listen empathically and to move in the frame of reference of the other person, and then come up with your own message).

6. Work synergistically (the whole is more than the sum of the parts; combine the strengths of people in positive teamwork, so that goals can be realized that no one could have realized alone).

7. Keep the saw sharp (maintain yourself well, both physically [condition, diet, stress], socialemotionally [service, empathy, synergy, inner security], spiritually [values, dedication, study] and mentally [read, write, plans], which helps to develop a sustainable, effective lifestyle).

The students work in groups of about 15 . In every meeting, a specific theme is central, often linked to one of Covey's habits. There is no classical form of teaching; the central focus is on what students learn from each other. Many experiences are exchanged and new things are tried during the meetings. It is intended that students connect their own lives with the seven habits of Covey, and their willingness to look at themselves is nurtured. Halfway through the course, there is an individual meeting with the teacher based on a reflection assignment. In this assignment, the students describe a situation that they themselves have experienced, on which they reflect using the first three habits. This means that the content relates to themselves, and that makes the feedback they receive in the conversation more personal.

\section{Student assessment}

There is no detailed and strict assessment. Personal development cannot be judged in the same way as knowledge and skills. However, a report can be made on the steps taken in the personal leadership development process, the use of the content of the course, the shown commitment, and contribution to the group. This report is discussed with fellow students and the teacher. Sometimes, this can lead to additions. The assessment by the teacher is based on the development experienced by the student and described in the final report (personal masterplan), a final presentation (a creative presentation, meaning not using a PowerPoint or similar software), participation during the meetings, and the contributions during discussions.

\section{Experiences}

In this section, experiences of the teachers are first described regarding the development process in the course towards a joint process, the organization within the course, the final assignment, and the personal development. Then students' experiences and the follow-up of the course are described.

-Development towards a joint process

'In the course, we don't define the exact learning outcomes for the students. The only assignment they receive is: Challenge yourself. We have a program for each meeting, but 
that is reasonably open, and we encourage the students to constantly think along and show leadership. If they want the evening to go differently, that happens. After a while, it becomes a joint process. This means that, as a teacher, you have less control and that you have to be able to respond to unexpected situations.

At the beginning of the course, the students are more closed and often find it "vague." Gradually, trust grows, and everyone dares to open up more. The number of students in the training groups (15) is an important quality driver. Having more students would truly be at the expense of the quality of the meetings. Students learn so much from each other. There is room for every opinion, for every perspective. They support each other and sometimes give each other very honest feedback, which is wonderful to see.'

\section{-Organization within the course}

'The physical layout of the classroom is very important to create that trust; the tables are set aside, and we are in a circle. This means students are not "safe" behind a table with a laptop. In this way, you create equality, focus on each other, and ensure that you are listened to. As a result of this, confidence grows. When the energy goes down, we often do an "energizer": a physical exercise to become more active again. There is also resistance to it ("Oh no, we have to jump again"), but it often has a positive effect. We experiment a lot with different work forms. We improvise and see what works. That is different in every group. We as teachers therefore also learn, and that can certainly be exciting. But, we also have to do ourselves what we ask of students. So, we step out of our comfort zone. That's what students feel as well, and that is, I think, the secret behind the success of this course.'

-The final assignment (personal master plan)

'The final assignment is a personal master plan, in which students describe their ideal leader on the basis of two heroes and reflections based on the seven habits of Covey. They also describe their development path and their personal mission. This implies a unique part of this course by making a strong connection between personal profiling and talent development. They can write a love letter to themselves for bonus points. We do not want to force that, so it is not a mandatory part of the assignment. In any case, they can give their own twist to the assignment. Most students write that love letter to themselves, and they always come to the core, which is wonderful to see! They also give a final presentation about what they have learned during the course. Those stories are always very special and sometimes emotional as well. It's nice to see how the students have grown in half a year and that they also know that they are not finished with that process yet.'

\section{-Personal development}

'The teachers and coaches involved give students the space and the confidence to do new things and make mistakes. Learning in the TopClass therefore extends beyond subjectrelated knowledge: it concerns personal development. Discover what you really find important and stand for your choices. Students therefore receive little guidance but learn to steer themselves. This is often accompanied by (learning to deal with) uncertainty and sometimes (overcoming) resistance. As a teacher, it is wonderful to be able to give such a course to honors students. I am proud of our students. I'm a little sad every time when we say goodbye to each other at the end of the course!'

It is important to create an atmosphere in which everyone can participate and that a mutual 
confidence grows, causing students to open up. This requires that the lecturers also open up, show things of their own, and show genuine interest. The group is essential for this type of learning, and, therefore, students have to share something in the group.

\section{-Experiences of students}

In evaluation, the majority of the students are overwhelmingly positive about the course. Frequently, students give the book by Covey as a gift to family members or other acquaintances. That has a lot to do with the space for personal attention. Students feel like they're being seen as people. They find the experience of being seen very exciting and sometimes difficult but also very inspiring.

During an interview, an alumna mentions the fact that she regards the leadership course as the place where she acquired a different perspective on things. She says: 'The characteristics of effective leadership described in Stephen Covey's book were important to me. You will also find these qualities in Buddhism. Using these characteristics as a basis, interactive meetings were organized. Students were also asked to write a reflection report, using the aforementioned characteristics. I still use the things I learned during the course in daily life, as it is useful on both a personal and professional level. This is possible due to the fact that we worked on efficient leadership very consciously for the duration of the course. Especially the concept of 'paradigm shift' that Covey often discussed has brought about a change. This creates more empathy for others, which leads to better contact with international people as well as with patients.' 'Sometimes, students only realize the importance of some things that have been discussed during the course, which is also part of the process of developing personal leadership. "Seeds" are planted, but they do not know whether they will germinate and grow later.' This also requires a different mindset from the supervising teachers.

-Follow-up

After the leadership course, students get to study more independently in the TopClass. They devise projects or research, go abroad or register for a course or premaster. For their honors program, they are supported by a coach. Although the teachers in the Personal Leadership course are also coaches, in practice, it means that most students get a coach that they barely know. This means that it can take some time to get used to each other because that coach did not share the process in the Personal Leadership course with that student. Every coach or teacher also has a different approach. That can cause insecurity again in the beginning but also a new stimulus, a situation that also requires personal leadership of the student. In the two years after the leadership course, students work independently and meet at TopClass community-meetings or TopClass workshops. We notice that many students fall into a kind of dip after the leadership course and that they need each other for inspiration and support and can give each other a huge boost. This is also a way to hear from each other about what everyone is doing and to make new plans together. Students often work together in (interdisciplinary) groups on an assignment or project. This is not devised by teachers or coaches but comes from the students themselves.

\section{Time requirement for teachers}

It is difficult to express the time investment in hours. Time is necessary for the meetings, the individual preparation, the preparation in the team of co-teachers, and reading and discussing portfolios, as well as other products of the students, which is about the usual time 
investment for such a course. But, it is also about preparing yourself mentally for the course and the development processes of students, which are unique for each student and, at the same time, ensuring that you don't fall into routine. That can affect the authenticity and openness of yourself to the students.

\section{Tips for teachers}

Tips are given for the preparation of the course and during the course.

\section{-Before the course}

Before the course, when it comes to the honors information events, it is of vital importance that enthusiastic honors coaches or coordinators are present in the different regular programs. They can inform the students about the honors program, including the leadership course, and possibly address suitable students and make them aware of these opportunities. The teachers have the impression that many more students than those who do an honors program have sufficient capacities to participate. Some students may not be ready for this personal development program. However, they might be ready later on in their studies. Preparation of teachers for this course now takes place through a basic orientation of teachers, individual preparation, and a joint talk, discussing the course meetings with fellow teachers. The latter is considered as being very important. From these joint talks, new, refreshing, ideas can come up. And, moreover, in this way, a start is made in the spirit of the course: the teachers also become more open and vulnerable to each other and willing to learn. This stimulates an open attitude to the students. New teachers must be well prepared for this program. They have to be socio-emotionally suitable, meaning, for example, that they also dare to be vulnerable towards the students and are able to stimulate them. Occasionally, coaching by teachers with more experience with this course is desirable.

\section{-During the course}

During the course, you are, as a teacher, a role model for your students. It is important for students that they feel heard. For example, it may be important to ask about their interests. By promoting mutual discussion, the process of community building can get started. Another tip is to give students control over their own workspace. This gives them a sense of ownership and gives them the opportunity to come up with their own plan, where they feel at home and can work well together. At the same time, at a certain moments, a teacher can also set limits to freedom (bounded freedom) when, for example, the situation is likely to become a mess.

There is often during the course a 'switch' moment for students, a moment in which students get to know how to take initiative and open up to you. For this to happen, the start of the course is important. The start weekend of this course was organized together with a 'Talent Center.' The Talent Center instructed coaches and student-assistants how to observe students and how to give them feedback on perceived talents during the start weekend. That worked extremely well (student: '[It was] so special; I've never experienced that before!'). Often, after two to three weeks in the course, the 'penny drops'; for example, there is a feeling of new possibilities and the realization that their life can look very different. Openness and social security in the course group are essential in this approach. The teacher is important, but the fellow students are as well. If three to four students are more open 
during a group discussion, the rest will follow automatically.

\section{Tips for students}

The tips for the students are for the choice to do this course and to their behavior and attitude during the course.

For students, it is important to really choose this course out of their personal interests and not feel compelled to do so by external forces. They also had to be able to do this course alongside their regular study program. If all their time is needed to do the regular program, participation in this course is not recommended.

During the course, students must be willing to share their experiences about their own development with fellow students in their course group and to open up to them (community). They have to prepare to listen to others, even though they might have experience and opinions which differ from their own, and to give constructive feedback.

Interest is expected from them to shape their process of development for personal leadership even though not everything is clear in advance, which can sometimes be difficult. Sufficient 'emotional intelligence' is required, that is, to be able to verbalize their own experiences and express their emotions, experience empathy for others, and, at least, minimal cooperation skills are required as well.

\section{Transfer to other programs}

The leadership course is given for students of the TopClass (the honors program) but is also offered to students who, at their own initiative, do all sorts of projects outside the TopClass to intensify and enrich their study. With this, they can earn 'individual honors stars.' This is a very mixed group of students in terms of both age, ranging from 17-42 years old, and previous education, with both full and part-time study programs in different educational programs related to Health Care.

The design and experiences of the leadership course was also an inspiration for the design of an honors program at the University of Amsterdam, The Netherlands (for medical students), and at another university of applied sciences.

\section{References, additional information and relation with Circle of Talent Development}

\section{$\underline{\text { References }}$}

Covey, S.R. (1989). The Seven Habits of Highly Effective People. London: Simon \& Schuster.

Eijl, P.J. van \& Pilot, A. (Eds.) (2016). The Honors Experience, talentontwikkeling door de ogen van de honorsstudent. Inspiratiebundel. [The Honors Experience, talent development through the eyes of honors students. Inspiration bundle.] Rotterdam: Uitgeverij Hogeschool Rotterdam. Available online:

https://www.researchgate.net/publication/305215269 The honors experience, talent dev elopment through the eyes of honors students synopsis 
Riteco, A., Kleyn, I, de \& Lamerichs, N. (2017). Honours and (re)design of the curriculum: How to bridge the gap between honours and bachelor programmes. Journal of the European Honors Council 1(1), 11. https://doi.org/10.31378/jehc.47

\section{$\underline{\text { Relation with Circle of Talent Development }}$}

In the introductory article of this issue of JEHC, the 'Circle of Talent Development' has been described. Based on interviews with forty honors students and literature about honors programs, it reflects relevant activities of students regarding the development of their talents in an honors program. The author of this note has been asked to score the good practice in relation to the activities in the Circle of Talent Development. The meaning of the scores is: + = somewhat important; ++ = moderately important; +++ = very important; $-=$ not applicable or irrelevant. The scores are intended to illustrate the strengths of a good practice for the reader.

Figure 1. Circle of Talent Development in relation with the good practice 'Honors course Personal Leadership' with the teacher's scores

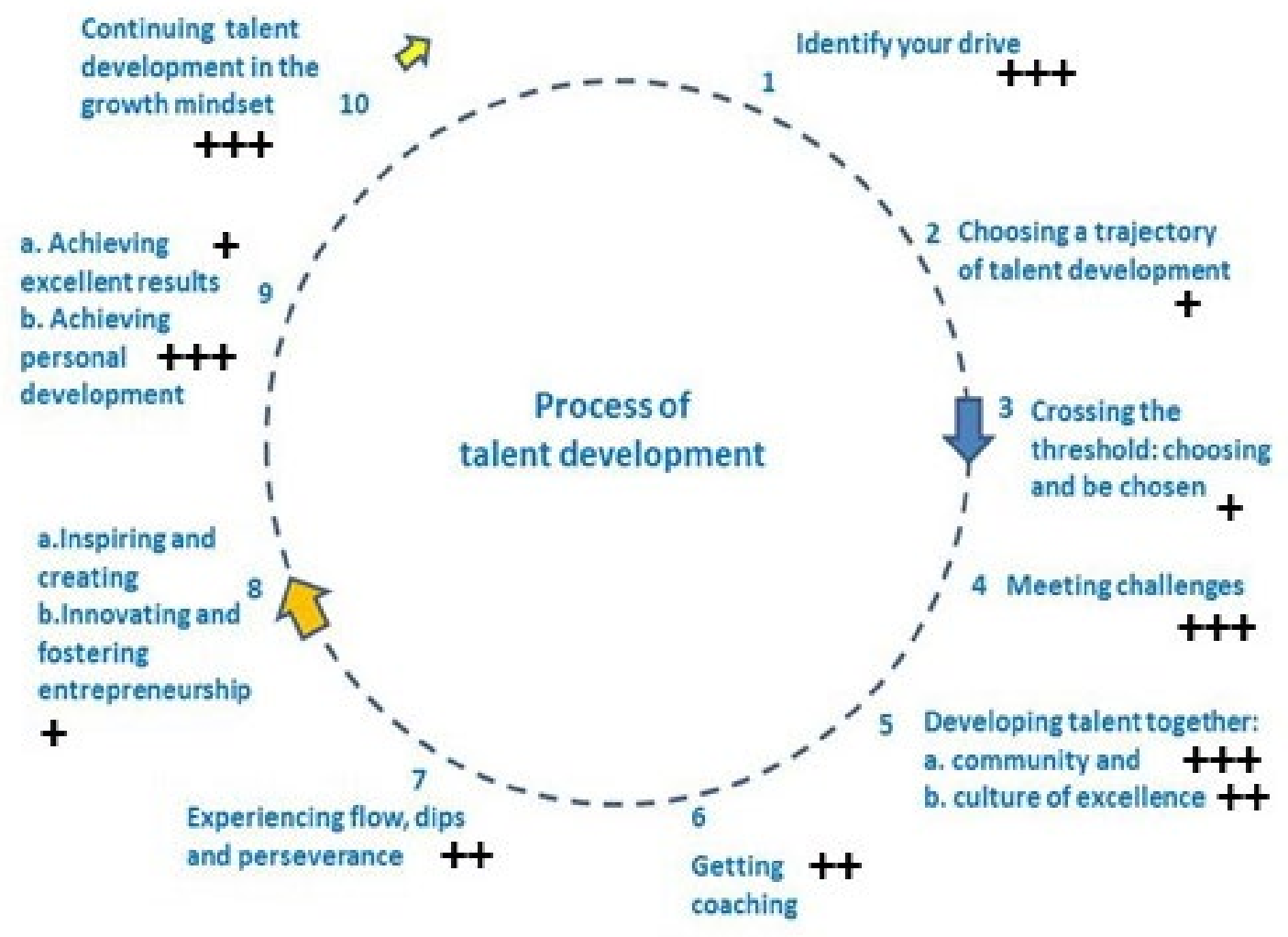

Question to the teacher: What makes this good practice attractive for other teachers?

The teacher of this practice argues: 'It's the possibility to stand beside the students and work on their personal development as well as your own. The central issue is to create challenges for yourself (student and teacher) related to the seven habits by Covey (1989) or otherwise connected to expand your possibilities and dreams to develop awareness and to focus on changing unwanted patterns in order to become more effective.' 